\title{
Enhanced stimulation of human tumor-specific $T$ cells by dendritic cells matured in the presence of interferon- $\gamma$ and multiple toll-like receptor agonists
}

\author{
Tanja Lövgren ${ }^{1,4,5}\left(D^{1} \cdot\right.$ Dhifaf Sarhan $^{1,2} \cdot$ Iva Truxová $^{1} \cdot$ Bhavesh Choudhary $^{1} \cdot$ Roeltje Maas $^{1} \cdot$ Jeroen Melief $^{1}$. \\ Maria Nyström $^{1} \cdot$ Ulrika Edbäck $^{1} \cdot$ Renee Vermeij $^{1} \cdot$ Gina Scurti $^{3} \cdot$ Michael Nishimura $^{3} \cdot$ Giuseppe Masucci $^{1}$. \\ Alex Karlsson-Parra ${ }^{4} \cdot$ Andreas Lundqvist $^{1} \cdot$ Lars Adamson $^{1} \cdot$ Rolf Kiessling $^{1}$
}

Received: 13 December 2016 / Accepted: 5 June 2017 / Published online: 10 June 2017

(C) The Author(s) 2017. This article is an open access publication

\begin{abstract}
Dendritic cell (DC) vaccines have been demonstrated to elicit immunological responses in numerous cancer immunotherapy trials. However, long-lasting clinical effects are infrequent. We therefore sought to establish a protocol to generate DC with greater immunostimulatory capacity. Immature DC were generated from healthy donor monocytes by culturing in the presence of IL-4 and GM-CSF and were further differentiated into mature DC by the addition of cocktails containing different cytokines and toll-like receptor (TLR) agonists. Overall, addition of IFN $\gamma$ and the TLR7/8 agonist R848 during maturation was essential for the production of high levels of IL-12p70 which was further augmented by adding the TLR3 agonist poly I:C. In addition, the DC matured with IFN $\gamma$, R848, and poly I:C also induced upregulation of several other
\end{abstract}

In part previously published in "Proceedings of the CRI-CIMT-

EATI-AACR Inaugural International Cancer Immunotherapy Conference: Translating Science into Survival," September 16-19, 2015, New York, NY, USA. Title: "Enhanced IL-12 production and $\mathrm{T}$ cell stimulation ability by dendritic cells matured in presence of GMP-grade Toll-like receptor ligands and IFN- $\gamma$," Cancer Immunol Res 2016;4(1 Suppl):Abstract nr B071.

Tanja Lövgren and Dhifaf Sarhan contributed equally to this work.

Electronic supplementary material The online version of this article (doi:10.1007/s00262-017-2029-4) contains supplementary material, which is available to authorized users.

Tanja Lövgren

tanja.lovgren@ki.se

1 Department of Oncology-Pathology, Cancer Center Karolinska, Karolinska Institutet, Stockholm, Sweden

2 Masonic Cancer Center, University of Minnesota, Minneapolis, MN, USA pro-inflammatory and Th1-skewing cytokines/chemokines, co-stimulatory receptors, and the chemokine receptor CCR7. For most cytokines and chemokines the production was even further potentiated by addition of the TLR4 agonist LPS. Concurrently, upregulation of the anti-inflammatory cytokine IL-10 was modest. Most importantly, DC matured with IFN $\gamma, \mathrm{R} 848$, and poly I:C had the ability to activate IFN $\gamma$ production in allogeneic $\mathrm{T}$ cells and this was further enhanced by adding LPS to the cocktail. Furthermore, epitope-specific stimulation of TCR-transduced $\mathrm{T}$ cells by peptide- or whole tumor lysate-loaded DC was efficiently stimulated only by DC matured in the full maturation cocktail containing IFN $\gamma$ and the three TLR ligands R848, poly I:C, and LPS. We suggest that this cocktail is used for future clinical trials of anti-cancer DC vaccines.

Keywords Cancer · Dendritic cell-vaccine $\cdot \operatorname{IFN} \gamma \cdot \mathrm{R} 848$. Poly I:C · LPS

$\begin{array}{ll}\text { Abbreviations } \\ \text { DAMP } & \text { Damage-associated molecular patterns } \\ \text { dsRNA } & \text { Double-stranded RNA } \\ \text { HSA } & \text { Human serum albumin } \\ \text { iDC } & \text { Immature DC } \\ \text { mDC } & \text { Mature DC } \\ \text { Mo-DC } & \text { Monocyte-derived DC }\end{array}$

3 Department of Surgery, Loyola University Chicago, Maywood, IL, USA

4 Department of Immunology, Genetics and Pathology, Uppsala University, Uppsala, Sweden

5 Cancer Center Karolinska R8:01, Karolinska Universitetssjukhuset Solna, 17176 Stockholm, Sweden 
MPLA-SM Monophosphoryl lipid A from Salmonella Minnesota

PAMP Pathogen-associated molecular patterns

PRR Pattern recognition receptors

PAP Prostatic acid phosphatase

PGE2 Prostaglandin E2

ssRNA Single-stranded RNA

\section{Introduction}

Efforts to vaccinate cancer patients with preparations of naturally occurring DC from blood has shown promising clinical results $[1,2]$. However, these primary DC are rare and therefore the majority of DC trials have been based on DC derived from monocytes ex vivo (Mo-DC). Monocytes are abundant in blood and large quantities of Mo-DC can be easily generated in culture for most individuals.

The FDA-approved DC-based vaccine (Sipuleucel-T, Provenge, Dendreon) consists of a leukapheresis product that has been enriched for DC precursors and loaded with a recombinant fusion protein of prostatic acid phosphatase (PAP) and GM-CSF. This cell product was shown to prolong the overall survival in asymptomatic or minimally symptomatic, metastatic, hormone-refractory prostate cancer patients by 4.1 months [3]. Unfortunately, the numerous other trials on Mo-DC vaccination conducted in different malignancies have had limited clinical success even though immunological responses were commonly reported in response to both unmutated tumor-associated antigens and mutated neoepitopes [4-7]. Thus, there is a need for more efficient Mo-DC vaccines and/or to combine Mo-DC vaccines with other therapies in cancer patients.

The in vitro generation of iDC from monocytes is most commonly stimulated by culturing in the presence of IL-4 and GM-CSF, but for triggering subsequent differentiation into $\mathrm{mDC}$ there are numerous different protocols. For an efficient $\mathrm{DC}$-based cancer vaccine, generated $\mathrm{mDC}$ have to be able to home to lymphoid tissue and, once there, efficiently stimulate tumor-specific Th1-type CD4+ T cells and CD8+ CTL that are able to eliminate tumor cells. To achieve this, mDC should express the lymph node homing receptor CCR7, high levels of co-stimulatory molecules such as CD80, CD83, and CD86 and produce high levels of the Th1skewing and CTL-stimulatory cytokine IL-12 [8-10].

For many years the gold standard for a maturation cocktail of DC vaccines contained TNF $\alpha$, IL- $1 \beta$, IL- 6 , and prostaglandin E2 (PGE2) [11]. However, these DC were shown to produce very little IL-12p70, which was attributed to the presence of PGE2 in the cocktail [12]. Thus, alternate cocktails without PGE2 were suggested. Most of these involve the addition of molecules containing pathogen- and/or damage-associated molecular patterns (PAMP and DAMP, respectively), which bind to pattern recognition receptors (PRR), such as TLR expressed by the DC. The TLR expression differs depending on the DC subtype and maturation stage. Monocyte-derived iDC have been reported to express several TLR, including TLR3, 4, and 8, receptors for double-stranded RNA (dsRNA), LPS, and singlestranded RNA (ssRNA), respectively [13-17]. In line with this, maturation cocktails containing a mixture of $\mathrm{TNF} \alpha$, IL $1 \beta$, IFN $\alpha$, IFN $\gamma$, and the TLR3 agonist poly I:C $[9,18]$, IFN $\gamma$ and poly I:C [19], IFN $\gamma$ and the TLR4 agonists LPS or its derivative monophosphoryl lipid A (MPLA) [19-23] or IFN $\gamma$ and the TLR7/8 agonist R848 [19, 21] generated $\mathrm{mDC}$ with improved IL-12p70 production while still expressing CCR7. Notably, the addition of IFN $\gamma[9,19$, $24,25]$ or combinations of more than one TLR agonist [24, 26, 27], (poly I:C and LPS, poly I:C and R848, LPS and R848) or both [28] (IFN $\gamma$, poly I:C, and R848 in combination with $\mathrm{CD} 40 \mathrm{~L}$ ) potentiated the IL-12p70 production. Furthermore, the addition of multiple TLR agonists also increased CCR7 expression [24, 26]. Therefore, we decided to study the T cell-activating capacity of DC matured with $\mathrm{TNF} \alpha$, IFN $\gamma$, and ligands for all three TLR expressed by Mo-DC (TLR3, 4, and 8), alone or in combination. The aim was to develop an improved DC vaccine by optimizing the maturation protocol to induce high IL-12p70 production, maintained CCR7 expression, and potent ability to activate tumor-specific $\mathrm{T}$ cells.

\section{Materials and methods}

\section{Cell preparation and culture}

PBMC were prepared from healthy blood donor buffy coats by Ficoll-Hypaque (GE Healthcare) density-gradient centrifugation. Purification of monocytes and $\mathrm{T}$ cells was performed by MACS (Miltenyi Biotec) using positive selection with CD14 microbeads or negative selection with pan $\mathrm{T}$ cell isolation kit, respectively, according to the manufacturer's instructions. Retroviral transduction of $\mathrm{T}$ cells with a TCR specific for tyrosinase ${ }_{368-376} 370 \mathrm{D}$ peptide was performed as previously described $[29,30]$.

The HLA-A2-positive A375 cell lines were cultured in DMEM (LifeTechnologies) supplemented with FCS (10\%), penicillin (100 U/ml; LifeTechnologies), and streptomycin $(100 \mu \mathrm{g} / \mathrm{ml}$; LifeTechnologies). Wild-type, tyrosinase-negative A375 cells and A375 cells transduced with SAMEN retrovirus encoding the Tyrosinase ${ }_{368-376} 370 \mathrm{D}$ epitope were used. The A 375 cells were harvested and diluted to $1.5 \times 10^{8} / \mathrm{ml}$ in GMP-grade CellGro ${ }^{\circledR}$ serum-free DC medium (CellGenix) + human serum albumin (HSA; $1 \%$; Octapharma). The cells were lysed by 6 cycles of freeze-thawing 
in liquid nitrogen and $56{ }^{\circ} \mathrm{C}$ water bath. The resulting lysate was passed through a $70 \mu \mathrm{M}$ cell strainer (Falcon). Protein concentration was measured using NanoDrop ${ }^{\mathrm{TM}}$ (Thermo Fischer Scientific).

Monocytes were cultured in $10 \mathrm{~cm}$ petri dishes (Corning) at $2 \times 10^{6}$ cells $/ \mathrm{ml}$ in $10 \mathrm{ml} \mathrm{CellGro}{ }^{\circledR}$ serum-free DC medium and differentiation was triggered by the addition of IL-4 (20 ng/ml; PeproTech) and GM-CSF (100 ng/ml; PeproTech) for $48 \mathrm{~h}$. The resulting immature DC were harvested and washed and thereafter cultured in 12 -well plates $\left(\mathrm{TPP}^{\circledR}\right)$ at $5 \times 10^{5}$ cells $/ \mathrm{ml}$, $2 \mathrm{ml} /$ well in CellGro ${ }^{\circledR}$ serum-free DC medium supplemented with IL-4 and GM-CSF as before and in addition combinations, as specified, of $\mathrm{TNF} \alpha(20 \mathrm{ng} / \mathrm{ml}$; PeproTech), IFN $\gamma$ (1000 IU/ml; Imukin ${ }^{\circledR}$, Boehringer Ingelheim), R848 $\left(2.5 \mu \mathrm{g} / \mathrm{ml}\right.$; VacciGrade ${ }^{\mathrm{TM}}$, Invivogen), Hiltonol@ (20 $\mu \mathrm{g} / \mathrm{ml}$; OncoVir), poly I:C (20 $\mu \mathrm{g} /$ $\mathrm{ml}$; Sigma-Aldrich or GE Healthcare), high and low molecular weight poly I:C (20 $\mu \mathrm{g} / \mathrm{ml}$; InVivoGen), LPS $\left(10 \mathrm{ng} / \mathrm{ml}\right.$; Sigma-Aldrich or VacciGrade ${ }^{\mathrm{TM}}$, InvivoGen), MPLA-SM (10 ng/ml; VacciGrade ${ }^{\mathrm{TM}}$, InVivogen), and A 375 cell lysates $(15 \mu \mathrm{g} / \mathrm{ml})$ for $18 \mathrm{~h}$ to generate mature dendritic cells. Where specified, peptide loading was performed after maturation, on harvested and washed DC, with either $10 \mu \mathrm{g} / \mathrm{ml}$ tyrosinase ${ }_{368-376}$ 370D peptide (YMDGTMSQV; Peptide 2.0) or HCV NS3 ${ }_{1406-1415}$ (KLVALGINAV; Peptide 2.0), as control peptide, in PBS for $1 \mathrm{~h}$ at $37{ }^{\circ} \mathrm{C}$ before thorough washing. In addition, the previously published "gold standard" [10 ng/ $\mathrm{ml}$ TNF $\alpha, 10 \mathrm{ng} / \mathrm{ml} \mathrm{IL1} \beta$ (CellGenix), 1000 IU/ml IL-6 (CellGenix), and $1 \mu \mathrm{g} / \mathrm{ml}$ PGE2 (Sigma-Aldrich)] [11]

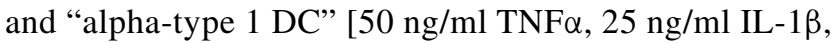
$3000 \mathrm{IU} / \mathrm{ml} \mathrm{IFN} \alpha$ (PBL assay science), $1000 \mathrm{IU} / \mathrm{ml}$ IFN $\gamma$, and $250 \mathrm{ng} / \mathrm{ml}$ Hiltonol())] [9] maturation cocktails were used for comparison during the iDC to $\mathrm{mDC}$ differentiation step where indicated.

$\mathrm{T}$ cell co-cultures were performed in round-bottom 96-well plates $\left(\mathrm{TPP}^{\circledR}\right)$ using CellGro ${ }^{\circledR}$ serum-free DC medium containing human $\mathrm{AB}$ serum $(2 \%)$ and IL-2 (20 IU/ml; Proleukin, Novartis). The DC were harvested and washed prior to co-culture. A ratio of $1 \mathrm{DC}$ $(25,000$ cells $)$ to $4 \mathrm{~T}$ cells $(100,000$ cells $)$ in $100 \mu \mathrm{l} /$ well was used and the co-cultures were incubated for 4 days. The selected setup was chosen to achieve the highest possible IFN $\gamma$ production without the need for medium exchange or splitting of wells. CD3/CD28 beads (LifeTechnologies) were used according to the manufacturer's instructions.

\section{Immunoassays}

ELISA for IFN $\gamma$ and IL-12p70 (MabTech) were performed according to the manufacturer's instructions. Standard curves were plotted as four-parameter sigmoidal curves and unknowns as well as p-values for linear regressions were calculated and plotted using GraphPad Prism (GraphPad).

Multiplex cytokine detection of 13 cytokines (IL1 $\beta$, IL-6, IL-8, IL-10, IL-12p70, IFN $\alpha 2$, IFN $\beta$, IFN $\lambda 1$, IFN $\lambda 2 / 3$, IFN $\gamma$, TNF $\alpha$, IP10, GM-CSF) was performed using the LEGENDPlex ${ }^{\mathrm{TM}}$ Human Anti-Virus Response panel (Biolegend) according to the manufacturer's instructions. The data were acquired on a NovoCyte (ACEA Biosciences) flowcytometer and analyzed using the provided LEGENDPlex 7.0 software. Heat maps were generated in Microsoft Excel (Microsoft).

\section{Flow cytometry}

Surface staining of DC for CD14 (clone M5E2, BioLegend), CD80 (clone 2D10, BioLegend), CD83 (clone HB15e, BioLegend), CD86 (clone IT2.2, BioLegend), HLA-DR (clone L243, BioLegend), CCR7 (clone 150503, BD Biosciences), IL-15R $\alpha$ (clone JM7A4, BioLegend), IL-15 (clone 34559, RD Systems), PD-L1 (clone MIH1, BD Biosciences), CD40 (clone 5C3, BD Biosciences), CD206 (clone 15-2, Biolegend), and DC-SIGN (clone 9E9A8, Biolegend) was performed for $20 \mathrm{~min}$ in the dark in PBS with HSA (1\%) at $4{ }^{\circ} \mathrm{C}$. Antibody concentration had been titrated for optimal signal-to-noise ratio. Data were acquired on a NovoCyte (ACEA Biosciences) or a BD ${ }^{\mathrm{TM}}$ LSR II (BD Biosciences) and analyzed using FlowJo Software (TreeStar) as geometric MFI or percent positive cells.

\section{Results}

\section{Enhanced IL-12p70 production by dendritic cells matured in presence of IFN $\gamma$, R848, and poly I:C}

In this study, we examined the effect of TNF $\alpha, \operatorname{IFN} \gamma$, and several TLR ligands independently or in combination on DC maturation. In a preliminary screening experiment, monocytes were purified from two healthy blood donors and used for maturation of dendritic cells. Throughout this study, the maturation was performed by a fast Mo-DC differentiation protocol, reported to result in DC with equal or better immune stimulatory capacity than previous longer protocols [23, 31-38]. Furthermore, we did a comparison with our previous 4 plus 2-day protocol and found no difference in DC viability or functionality (results not shown). Thus, monocytes were cultured for an initial $48 \mathrm{~h}$ in serum-free DC medium supplemented with GM-CSF and IL- 4 followed by harvest and washing and thereafter $18 \mathrm{~h}$ in the same medium but with additional combinations of TNF $\alpha$, IFN $\gamma$, the TLR7/8 agonist R848, and/or the GMP-grade poly I:C Hiltonol@ before measuring IL-12p70 


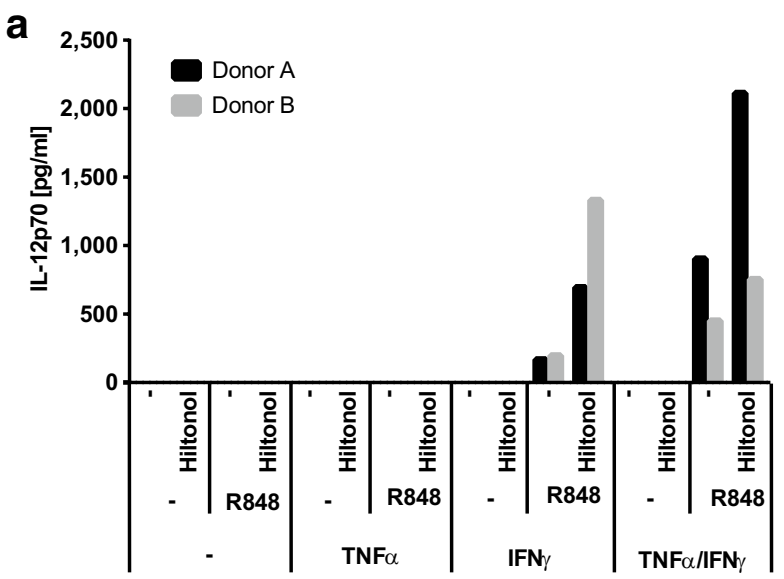

b IL1 $\beta$ IL-6 IL-8

IP10

IL-12p70

\begin{tabular}{r|ccc||ccc||} 
& \multicolumn{2}{c}{ Donor C Donor D Donor E } & \multicolumn{1}{c}{ Donor C Donor D Donor E } \\
iDC & ND & ND & 14 & 17 & 130 & 15 \\
TNF $\alpha$ & ND & ND & ND & 160 & 190 & 51 \\
TNF $\alpha+$ LPS & ND & ND & ND & 21,000 & 450 & 810 \\
LPS & 430 & ND & ND & 111,189 & 320 & 4,700 \\
R848+LPS & 5,200 & 100 & 310 & 170,000 & 50,000 & 93,000 \\
IFN $\gamma+$ LPS & 290 & 18 & ND & 83,000 & 1,600 & 5,200 \\
Hiltonol+LPS & 830 & 18 & 21 & 110,000 & 630 & 11,000 \\
IFN $\gamma+$ R848+Hiltonol & 81 & 160 & 130 & 29,000 & 33,000 & 39,000 \\
IFN $\gamma+$ R848+Hiltonol+LPS & 2,600 & 180 & 270 & 150,000 & 53,000 & 140,000 \\
\cline { 2 - 3 } & & & & &
\end{tabular}

Donor C Donor D Donor E
\begin{tabular}{|ccc|}
\hline 130 & 14,000 & 320 \\
9,000 & 21,000 & 8,000 \\
\hline 170,000 & 28,000 & 31,000 \\
\hline 280,000 & 12,000 & 16,000 \\
\hline 230,000 & $2.2 E+06$ & 330,000 \\
\hline 56,000 & 14,000 & 4,600 \\
\hline 220,000 & 14,000 & 31,000 \\
\hline 30,000 & $1.0 E+06$ & 130,000 \\
\hline 98,000 & $1.2 E+06$ & 300,000 \\
\hline
\end{tabular}

Donor C Donor D Donor E
\begin{tabular}{|ccc|ccc|}
\hline 21 & 37 & 38 & \multicolumn{4}{|c}{ Donor C Donor D Donor E } \\
ND & 38 & ND & 7 & 7 & 5 \\
170 & 34 & 98 & 380 & 8 & 16 \\
2,500 & 24 & 1,800 & 2,200 & 10 & 63 \\
410 & 45 & 400 & 1,100 & 400 & 1,100 \\
28,000 & 4,000 & 26,000 & 13,000 & 19 & 340 \\
\hline 49,000 & 2,400 & 130,000 & 1,700 & 8 & 240 \\
\hline 130,000 & 33,000 & 120,000 & 4,700 & 6,200 & 16,000 \\
\hline 42,000 & 32,000 & 130,000 & 43,000 & 5,000 & 31,000 \\
\hline
\end{tabular}

IFN $\beta$

IFN $\lambda 1$

IFN $\gamma^{*}$

$\mathrm{TNF} \alpha^{*}$

IL-10

\begin{tabular}{r|ccc||ccc||} 
& \multicolumn{1}{c}{ Donor C Donor D Donor E } & \multicolumn{4}{c}{ Donor C Donor D Donor E } \\
IDC & 37 & 140 & 19 & ND & 63 & ND \\
TNF $\alpha$ & 51 & 100 & 38 & 81 & 58 & 49 \\
TNF $\alpha+$ LPS & 110 & 130 & ND & 254 & 63 & 72 \\
LPS & 250 & 38 & 30 & 464 & 78 & ND \\
R848+LPS & 310 & 130 & 57 & 408 & 104 & 99 \\
IFN $\gamma+$ LPS & ND & 79 & 12 & 981 & 51 & ND \\
Hiltonol+LPS & 240 & 71 & 47 & 450 & 63 & 261 \\
\hline IFN $\gamma+$ R848+Hiltonol & 320 & 280 & 320 & 582 & 436 & 719 \\
IFN $\gamma+$ R848+Hiltonol+LPS & 170 & 300 & 250 & 1,841 & 441 & 1,064 \\
\hline
\end{tabular}

\begin{tabular}{|c|c|c|c|c|c|c|c|c|}
\hline \multicolumn{3}{|c|}{ Donor C Donor D Donor E } & \multicolumn{3}{|c|}{ Donor C Donor D Donor E } & \multicolumn{3}{|c|}{ Donor C Donor D Donor E } \\
\hline 24 & 37 & 20 & 5 & 170 & 8 & 4 & 10 & 5 \\
\hline 23 & 31 & 25 & 10,000 & 6,800 & 11,000 & 6 & 10 & 3 \\
\hline 77 & 35 & 20 & 14,000 & 4,200 & 8,500 & 290 & 11 & 16 \\
\hline 120 & 22 & 21 & 19,000 & 140 & 450 & 830 & 10 & 16 \\
\hline 210 & 40 & 34 & 27,000 & 210,000 & 12,000 & 13,000 & 3,700 & 5,600 \\
\hline 65,000 & 53,000 & 47,000 & 17,000 & 1,500 & 230 & 53 & 8 & 4 \\
\hline 86 & 34 & 25 & 21,000 & 260 & 1,600 & 970 & 12 & 42 \\
\hline 100,000 & 210,000 & 210,000 & 14,000 & 180,000 & 28,000 & 1,400 & 780 & 1,200 \\
\hline 92,000 & 220,000 & 230,000 & 40,000 & 200,000 & 36,000 & 5,900 & 970 & 4,400 \\
\hline
\end{tabular}

C

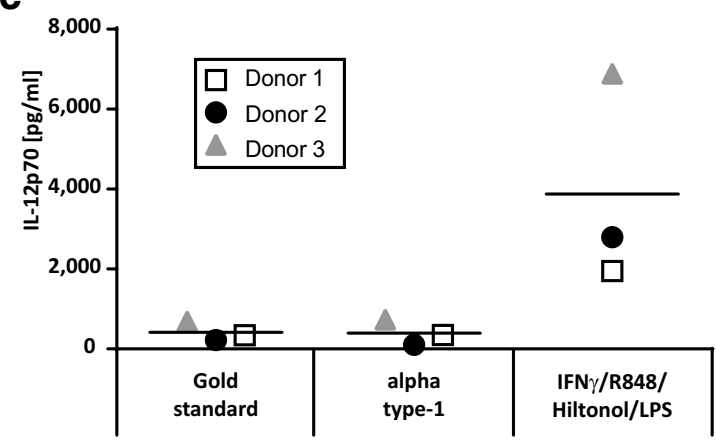

in the cultures (Fig. 1a). Notably, the maturation protocol with $\mathrm{TNF} \alpha$ alone induced very little IL-12p70 production. The maturation cocktail containing IFN and R848 showed efficient IL-12p70 production, which was further increased after the addition of Hiltonol $\odot$. Adding TNF $\alpha$ to the other reagents had variable effect between the donors.

In an effort to further enhance the DC product, we evaluated the effect of additional TLR triggering by including the 
4Fig. 1 Production of cytokines by monocyte-derived dendritic cells matured in the presence of different stimulatory cocktails. Monocytes from two donors were screened for the production of IL-12p70 after an initial $48 \mathrm{~h}$ culture with GM-CSF/IL-4 followed by harvest, wash, and thereafter $18 \mathrm{~h}$ with GM-CSF/IL-4 together with different combinations of TNF $\alpha$, IFN $\gamma, \mathrm{R} 848$, and the GMP-grade poly I:C Hiltonol $^{\circledR}$ (a). Monocytes from three donors were matured into mDC with the same stimulators as above and also LPS. The supernatants were screened for the production of a panel of different cytokines (b). Numbers represent concentrations $(\mathrm{pg} / \mathrm{ml})$ of the respective cytokine and the gray scale represents the lowest (white) to highest (black) concentrations within each donor. Stars indicate that the measured cytokine was added to some cocktails $(\sim 35,000 \mathrm{pg} / \mathrm{ml} \mathrm{IFN} \gamma$ or $20,000 \mathrm{pg} / \mathrm{ml} \mathrm{TNF} \alpha)$. Monocytes from three donors were screened for the production of IL-12p70 after an initial $48 \mathrm{~h}$ culture with GMCSF/IL-4 followed by $18 \mathrm{~h}$ with IFN $\gamma, \mathrm{R} 848$, Hiltonol, and LPS or with the "gold standard" (TNF $\alpha$, IL1 $\beta$, IL-6, PGE2) and "alpha type1 ” (TNF $\alpha$, IL-1 $\beta$, IFN $\alpha$, IFN $\gamma$, Hiltonol) DC cocktail (c)

TLR4 agonist LPS in the DC maturation cocktails. Released cytokines were evaluated using a multiplex assay measuring 13 different cytokines of mainly Th1 type. Many of these (IL1 $\beta$, IL-6, IL-8, IL-10, IL-12p70, IFN $\beta$, IFN $\lambda 1$, IP10, IFN $\gamma, \mathrm{TNF} \alpha$ ) were upregulated already in the IFN $\gamma, \mathrm{R} 848$, and Hiltonol(C-matured DC compared to $\mathrm{TNF} \alpha$-matured DC (Fig. 1b). However, the production of most cytokines was further increased upon addition of LPS. Some were only weakly detected in any condition (IFN $\alpha 2, \operatorname{IFN} \lambda 2 / 3$; results not shown) and others have to be evaluated with caution since they were exogenously added to some conditions (IFN $\gamma, \mathrm{TNF} \alpha, \mathrm{GM}-\mathrm{CSF}$; results not shown for GM-CSF). However, higher TNF $\alpha$ levels were detected in supernatant from DC matured with IFN $\gamma, \mathrm{R} 848$, and Hiltonol with or without LPS, than in conditions where TNF $\alpha$ was added. Similarly, IFN $\gamma$ was detected in greater levels in IFN $\gamma$, R848, and Hiltonol@-matured DC than the added amount.

Other cocktails generally induced much weaker cytokine induction than IFN $\gamma$, R848, and Hiltonol@-containing ones (with or without LPS). An exception was the combination of R848 and LPS. However, the R848 and LPS mixture induced much lower levels of IL-12p70 and IP10 while it induced the highest level of anti-inflammatory IL-10. The IL-10 level was upregulated also in IFN $\gamma, \mathrm{R} 848$, and Hiltonol(C-matured DC (with or without LPS) but only modestly compared to pro-inflammatory cytokines/ chemokines, such as IL6, IL-8, IP-10, and IL-12p70. Thus, for activating anti-tumor $\mathrm{T}$ cell responses, the combination of IFN $\gamma$, R848, Hiltonol@, and LPS displayed the most promising cytokine profile. To confirm the findings, the IFN $\gamma$, R848, Hiltonol@, and LPS combination was further compared to two previously published and commonly used DC maturation cocktails; the "gold standard DC" (TNF $\alpha$, IL1 $\beta$, IL-6, PGE2) [11] and the "alpha type-1 DC" (TNF $\alpha$, IL-1 $\beta$, IFN $\alpha$, IFN $\gamma$, Hiltonol) [9] cocktails. None of these were induced as high levels of IL12p70 as DC cultures matured with IFN $\gamma$, R848, Hiltonol $\odot$, and LPS (Fig. 1c).

\section{GMP-grade poly I:C Hiltonol is as effective as non-GMP-grade poly $\mathrm{I}: \mathrm{C}$ to induce IL-12p70 production in $\mathrm{DC}$}

To further assess the effect of poly I:C on DC IL-12p70 production, we studied the effect of different variants of poly $\mathrm{I}: \mathrm{C}$ on DC maturation. Poly $\mathrm{I}: \mathrm{C}$ is a heterogeneous product consisting of dsRNA of different length and the exact composition may differ between batches. Furthermore, structural changes may be introduced, for example to stabilize the product. Finally, non-GMP-grade poly I:C was occasionally found to be contaminated with LPS (results not shown). Hiltonol $C$ is a GMP-grade, long-strand poly $\mathrm{I}$ C, stabilized by a poly-lysine chain. Hiltonol was compared to two non-GMP-grade, mixed-length, unstabilized poly $\mathrm{I}: \mathrm{C}$ for its ability to stimulate iDC when combined with IFN $\gamma$ and R848. Hiltonol@ and non-GMP-grade poly I:C from Sigma-Aldrich induced similar amounts of IL12 p70 while non-GMP-grade, unstabilized poly I:C from GE Healthcare induced much lower levels of IL-12p70 (Fig. 2a).

Further experiments showed no difference in IL-12p70 induction in DC when comparing low or high molecular weight poly I:C (results not shown). Addition of LPS to the maturation cocktail, on the other hand, strongly increased the IL-12p70 production (Fig. 2b). In contrast, addition of $\mathrm{TNF} \alpha$ to maturation cocktails that lacked LPS had no effect (Fig. 2a) and decreased the IL-12p70-inducing capacity of maturation cocktails containing LPS (Fig. 2b). In summary, we conclude that the combination of IFN $\gamma$, R848, poly I:C, and LPS was the most efficient inducer of IL-12p70 production in DC and that GMP-grade poly I:C Hiltonol was as good or better than non-GMP-grade poly $\mathrm{I}: \mathrm{C}$.

\section{The ability of dendritic cells to activate allogeneic $\mathbf{T}$ cells correlates with their production of IL-12p70}

Matured dendritic cells were harvested and washed before being co-cultured for 4 days with allogeneic $\mathrm{T}$ cells in mixed leukocyte reactions. Thereafter, supernatants were assessed for IFN $\gamma$ production. Capacity of DC to stimulate IFN $\gamma$ production in allogeneic T cells (Fig. 2c, d) correlated significantly with their ability to produce IL-12p70 (Fig. 3). Finally, DC alone also produced IFN $\gamma$ but only a fraction of what was produced by $\mathrm{T}$ cell co-cultures (Suppl Fig. 1a, b). Thus, from these initial experiments we decided to go on to compare the maturation cocktail containing the GMP-grade poly I:C Hiltonol $C$ in combination with IFN $\gamma$ and R848, with TNF $\alpha$ alone that has been used by us and others in earlier cancer DC vaccine trials [39-41]. In addition we decided to test both variants with or without the addition of LPS. 
a

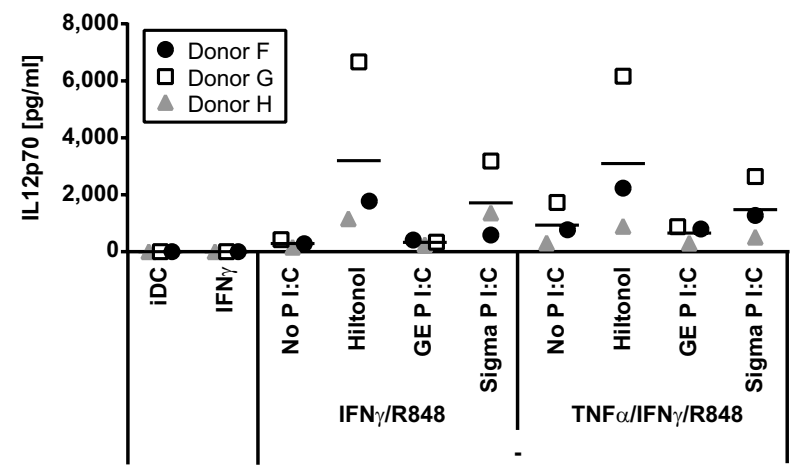

C

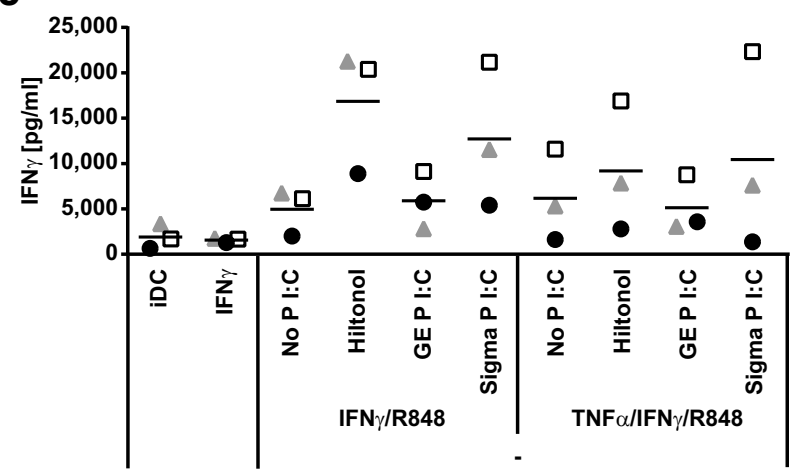

Fig. 2 Activation of allogeneic $\mathrm{T}$ cells by monocyte-derived dendritic cells matured in the presence of different stimulatory cocktails. Monocytes from three donors were analyzed for the production of IL-12p70 after an initial $48 \mathrm{~h}$ culture with GM-CSF/IL-4 followed by harvest, wash, and thereafter $18 \mathrm{~h}$ with GM-CSF/IL-4/IFN $\gamma /$ R848 together with combinations of $\mathrm{TNF} \alpha$ and GMP-grade poly I:C

DC matured in presence of IFN $\gamma$, R848, and poly I:C express increased levels of co-stimulatory molecules, activation markers, and CCR7

Differently matured DC were analyzed for the expression of surface markers (Fig. 4). All maturation protocols induced upregulation of CD80 (Fig. 4a), CD83 (Fig. 4b), CD86 (Fig. 4c), HLA-DR (Fig. 4d), IL-15R $\alpha$ (Fig. 4f), and membrane-bound IL-15 (Fig. 4g) compared to iDC. However, upregulation of CD80, CD83, CD86, and IL-15R $\alpha$ expression as well as increase in membrane-bound IL-15 in DC was much stronger in DC when matured with IFN $\gamma$, R848, and Hiltonol $\odot$ than with TNF $\alpha$. Furthermore, upregulation of CCR7 (Fig. 4e) was only achieved with cocktails containing IFN $\gamma$, R848, and Hiltonol@. On the other hand, HLA-DR expression was increased by TNF $\alpha$ DC but only marginally by combinations containing IFN $\gamma, \mathrm{R} 848$, and Hiltonol@ (Fig. 4d). In addition, presence of the co-inhibitory molecule PD-L1 was only induced by IFN $\gamma$, R848, and Hiltonol@-containing cocktails (Fig. 4h). The effect b

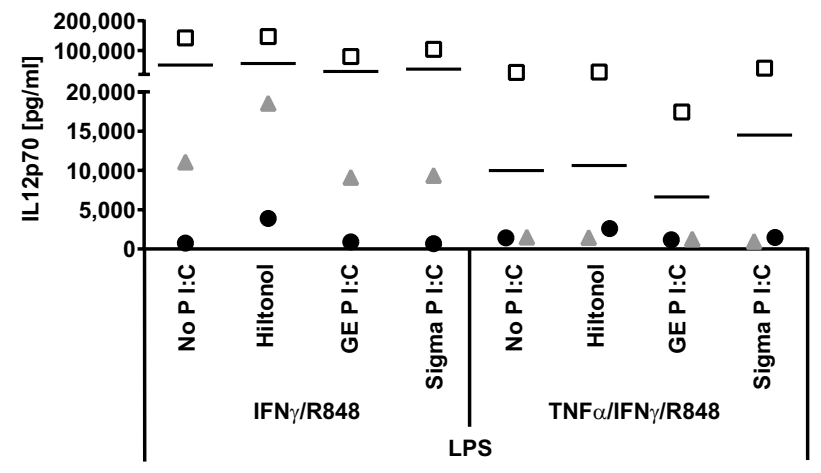

d

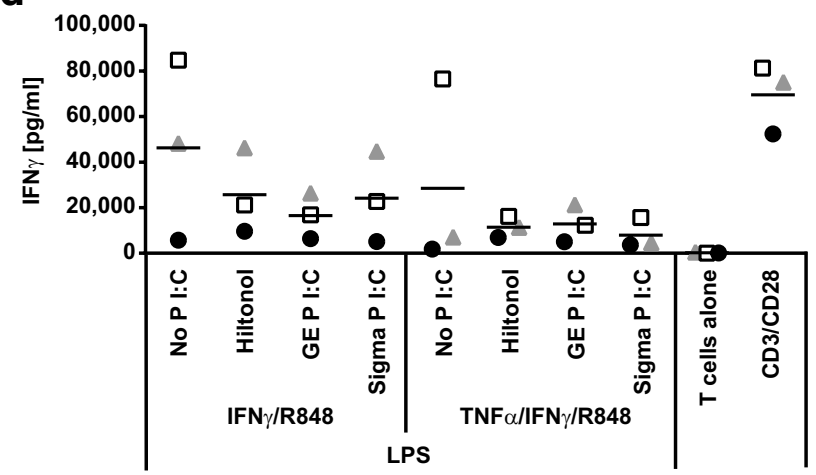

Hiltonol ${ }^{\circledR}$ or non-GMP-grade poly I:C from either GE Healthcare or Sigma-Aldrich without (a) or with addition of LPS (b). The monocyte-derived dendritic cells were harvested, washed, and then co-cultured for 4 days with allogeneic bulk $\mathrm{T}$ cells before the analysis of IFN $\gamma$ production $(\mathbf{c}, \mathbf{d})$. Note the difference in scales of $y$-axes

of different maturation alternatives on the expression of CD14, DC-SIGN, mannose receptor, and CD40 was variable between individuals (results not shown). Furthermore, presence of LPS in cocktails had limited effect on the expression of DC surface markers, and the effect varied between donors.

\section{Specific activation of $T$ cells by peptide-loaded DC following maturation in the presence of IFN $\gamma, \mathbf{R 8 4 8}$, poly I:C, and LPS}

Dendritic cell stimulation of $\mathrm{T}$ cells transduced with a TCR specific for a tyrosinase-derived peptide presented in HLA-A2 was used as a model for specific T cell activation. Monocytes were purified from HLA-A2-positive blood donors and matured as described. Production of IL12 p70 corresponded well with previous experiments and DC matured in the cocktail combining IFN $\gamma$, R848, Hiltonol@, and LPS was clearly the most efficient IL-12p70 producers (Suppl Fig. 2a). After maturation, generated DC were either left unloaded, loaded with tyrosinase peptide, 
Fig. 3 Correlation between IL12 p70 production in dendritic cells and IFN $\gamma$ production by allogeneic bulk $\mathrm{T}$ cells stimulated with these dendritic cells. The amount of IL-12p70 produced by monocyte-derived dendritic cells matured by different maturation cocktails was compared to their ability to, after harvest and wash, induce IFN $\gamma$ production in allogeneic $\mathrm{T}$ cells during a 4-day co-culture. Depicted are cytokine levels for 7 donors and $p$-values for linear regression
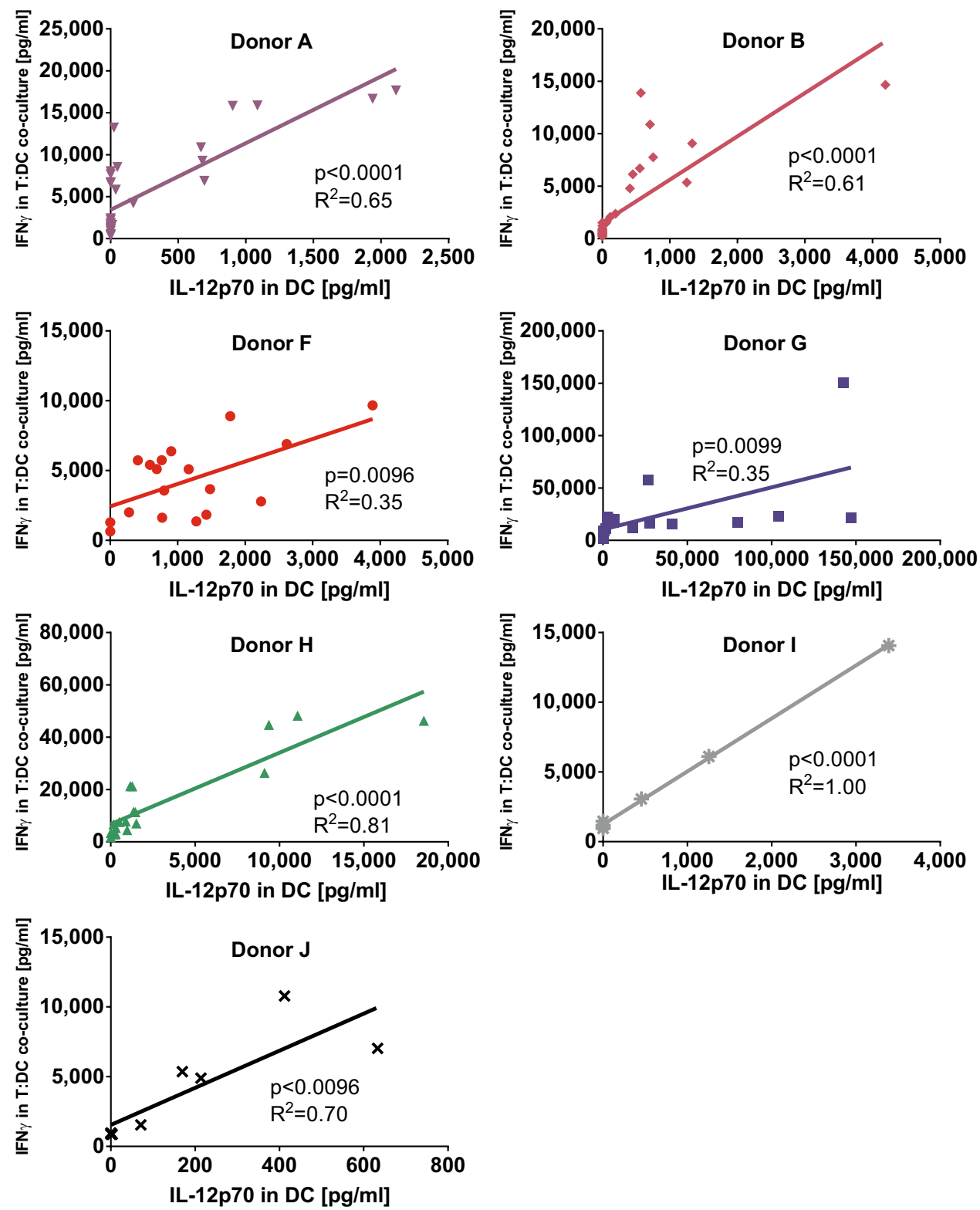

or a control HCV peptide. Next, DC were co-cultured with tyrosinase TCR-transduced T cells for 4 days before IFN $\gamma$ production was analyzed. Since these $T$ cells in addition to the transduced TCR have an endogenous TCR, there is alloreactivity against unloaded donor DC. Thus, in keeping with previous data, levels of IFN $\gamma$ produced in co-cultures of $\mathrm{T}$ cells and unloaded DC corresponded well with the IL-12p70 produced by the DC, being highest with DC matured in the presence of IFN $\gamma$, R848, Hiltonol $\odot$, and LPS (Suppl Fig. 3a). This alloreactivity was in most cases slightly decreased when HCV control peptide was added, probably due to competitive binding to MHC molecules (Suppl Fig. 3c). Finally, compared to alloreactive responses, IFN $\gamma$ production was increased in response to tyrosinase peptide-loaded DC (Suppl Fig. 3e, DC controls: Suppl Fig. 2c, T cell controls: Suppl Fig. 3 g). To calculate the amount of specific activation of $\mathrm{T}$ cells, background IFN $\gamma$ produced in response to control $\mathrm{HCV}$ peptide-loaded DC was subtracted from that produced in response to tyrosinase peptide-loaded DC (Fig. 5a). Results showed that only DC matured with IFN $\gamma, \mathrm{R} 848$, Hiltonol@, and LPS could efficiently activate peptide-specific IFN $\gamma$ production in tyrosinase-specific T cells.

DC matured in presence of IFN $\gamma, \mathbf{R 8 4 8}$, poly I:C, and LPS are able to process and present whole antigen and activate specific $T$ cells

Next, ability of the matured DC to process and present whole antigen from tumor cells was determined. Cell 
a

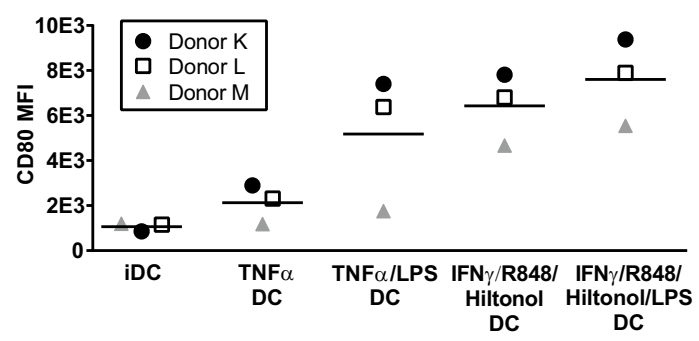

C

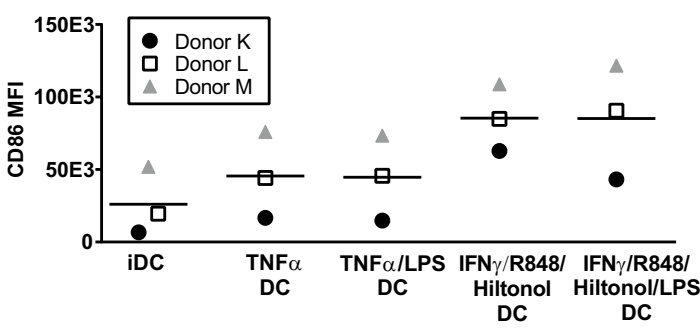

e

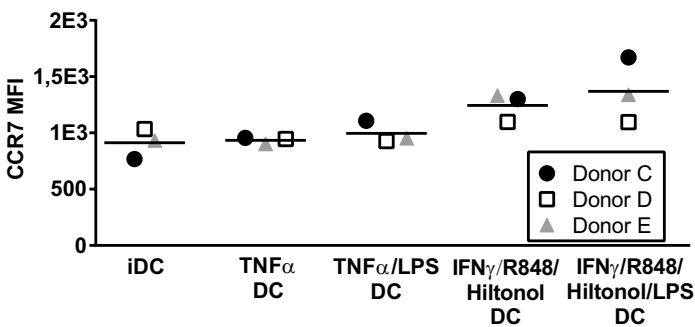

g

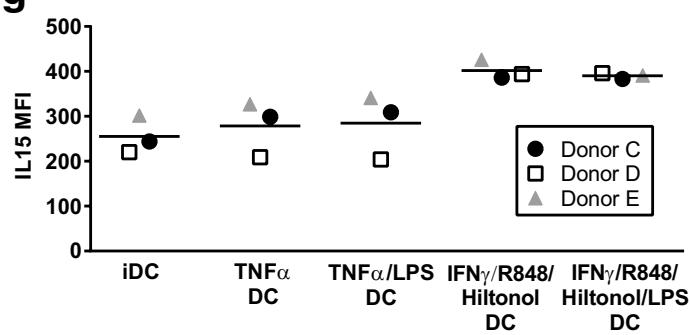

Fig. 4 Expression of maturation markers by monocyte-derived dendritic cells matured with different stimulatory cocktails. Monocytes from three donors were cultured for $48 \mathrm{~h}$ with GM-CSF/ IL-4 followed by harvest, wash, and thereafter $18 \mathrm{~h}$ with GM-CSF/ IL-4 together with different combinations of TNF $\alpha$, IFN $\gamma, \mathrm{R} 848$,

lysates from tyrosinase-positive or tyrosinase-negative A375 melanoma cells were added to DC during the second maturation step. In these experiments, either LPS from Sigma-Aldrich or VacciGrade ${ }^{\mathrm{TM}}$ LPS from InVivogen or VacciGrade ${ }^{\text {TM }}$ MPLA-SM (an LPS derivative, purified from Salmonella Minnesota) was used to activate TLR4. Amounts of IL-12p70 produced by DC followed a similar trend as in the previous experiments being highest after IFN $\gamma$, R848, Hiltonol@, and LPS maturation (Suppl Fig. 2b). The purity of the LPS did not change the results (results not shown), but it was clear that intact LPS was b
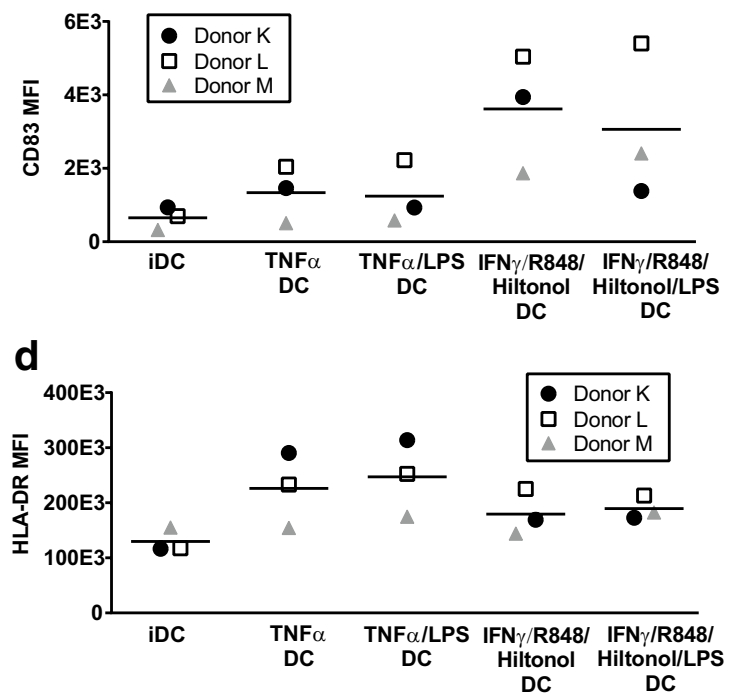

f

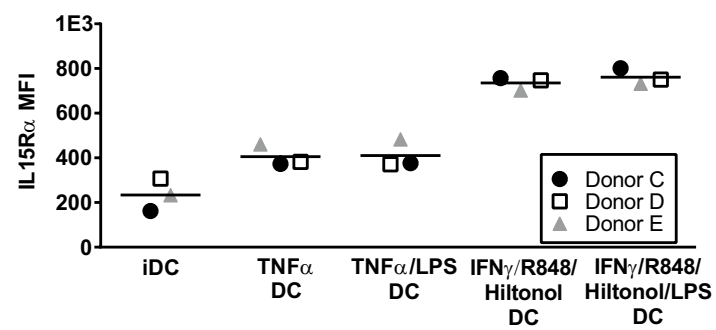

h

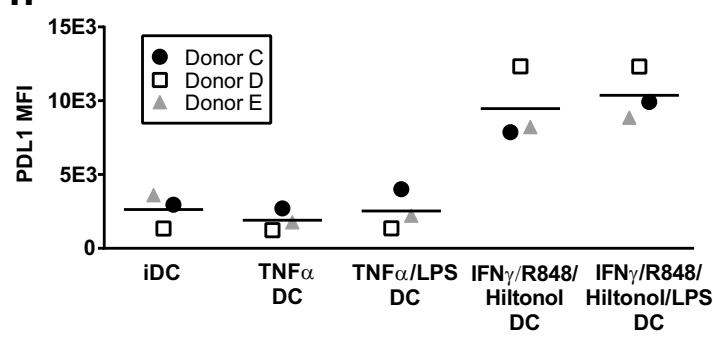

the GMP-grade poly I:C Hiltonol ${ }^{\circledR}$, and LPS. Thereafter the surface expression of CD80 (a), CD83 (b), CD86 (c), HLA-DR (d), CCR7 (e), IL-15R $\alpha$ (f), surface-bound IL-15 (g), PDL1 (h), was assessed by flow cytometry. Depicted values are mean fluorescent intensities

needed as the LPS derivative MPLA-SM did not increase IL-12p70 production in this setting (Suppl Fig. 2b). A synthetic variant of MPLA was also tested, with no effect on IL-12p70 production (results not shown). Following maturation, antigen-loaded DC were co-cultured with tyrosinase TCR-transduced T cells for 4 days before measuring IFN $\gamma$. As observed in previous experiments, strongest alloreactive production of IFN $\gamma$ in responses to unloaded DC was measured after maturation with IFN $\gamma$, R848, Hiltonol@ and LPS (Suppl Fig. 3b). DC loaded with tyrosinase-negative A375 lysate induced very similar levels of IFN $\gamma$ in T 

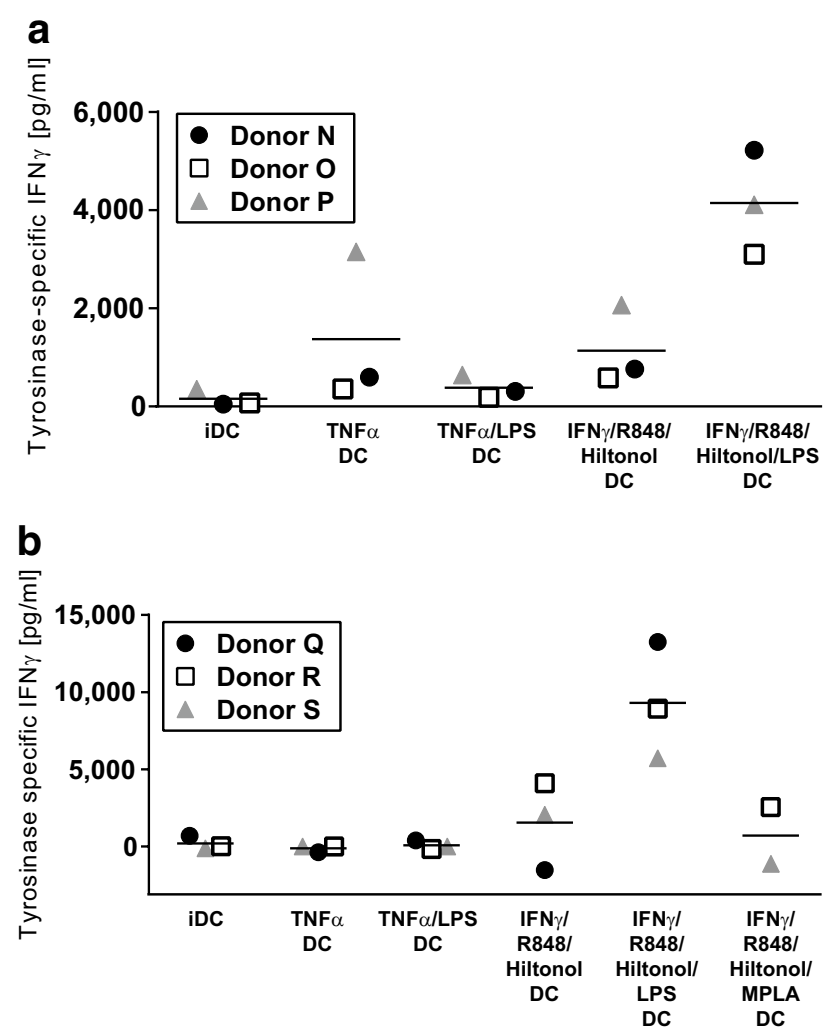

Fig. 5 Activation of tyrosinase-specific $\mathrm{T}$ cells by tyrosinase-loaded monocyte-derived dendritic cells matured in the presence of different stimulatory cocktails. Monocytes from six donors were analyzed for the production of IL-12p70 after an initial $48 \mathrm{~h}$ culture with GM-CSF/IL-4 followed by harvest, wash, and thereafter $18 \mathrm{~h}$ with GM-CSF/IL-4 together with the combinations of IFN $\alpha$, TNF $\gamma$, R848, GMP-grade poly I:C Hiltonol ${ }^{\circledR}$, different forms of LPS, and/ or monophosphoryl Lipid A (MPLA). The mature monocyte-derived dendritic cells from the first three donors were then harvested, washed, and either kept unloaded or pulsed with tyrosinase or HCV peptide and co-cultured with allogeneic tyrosinase-specific TCRtransduced $\mathrm{T}$ cells. Specific activation was calculated by subtracting the IFN $\gamma$ response against the control $\mathrm{HCV}$ peptide-loaded DC from the IFN $\gamma$ response against the tyrosinase peptide-loaded DC (a). For the last three donors, tumor cell lysate from either tyrosinase-negative A375 cells or tyrosinase-transduced A375 was added during the maturation from immature to mature dendritic cells. Thereafter the dendritic cells were harvested, washed, and co-cultured with the tyrosinase-specific T cells. Specific activation was calculated by subtracting the IFN $\gamma$ response against the control A375 lysate-loaded DC from the IFN $\gamma$ response against the tyrosinase-expressing A375 lysateloaded DC (b)

cells as the unloaded DC (Suppl Fig. 3d). However, T cells co-cultured with tyrosinase-positive A375 lysate-loaded DC produced increased levels of IFN $\gamma$ (Suppl Fig. 3f, DC controls: Suppl Fig. 2d, T cell controls: Suppl Fig. 3 h). Specific $\mathrm{T}$ cell activation was measured by subtracting the amount of IFN $\gamma$ produced by $\mathrm{T}$ cells co-cultured with tyrosinase-negative A375 lysate-loaded DC from the amount of IFN $\gamma$ produced against tyrosinase-positive A375 lysate-loaded DC (Fig. 5b). Our data revealed that only DC matured in the presence of IFN $\gamma$, R848, Hiltonol@ $\odot$, and LPS could efficiently induce specific activation of IFN $\gamma$ production in T cells.

\section{Discussion}

In the current study, we show that DC matured in the presence of a combination of IFN $\gamma$ and ligands for TLR3 (poly I:C), TLR4 (LPS), and TLR8 (R848) display features crucial for triggering efficient $\mathrm{T}$ cell-mediated anti-tumor responses. This includes production of pro-inflammatory and Th1-skewing cytokines/chemokines such as IL-12p70, IL1 $\beta$, IL-6, IL-8, IP-10, TNF $\alpha$, and type 1, 2, and 3 IFN and increased expression of co-stimulatory molecules such as $\mathrm{CD} 80, \mathrm{CD} 83$, and CD86, the cytokine receptor IL-15R $\alpha$ as well as surface-bound IL-15, and the lymph node homing receptor CCR7. Most importantly, these DC had the ability to activate $\mathrm{T}$ cells unspecifically through allogenic stimulation or specifically via peptide loading or via engulfment of antigen-containing tumor cell lysates.

DC matured in the presence of IFN $\gamma$, TLR3, and TLR8 agonists but without LPS expressed similar levels of all surface markers as when LPS was added, but produced much lower levels of most cytokines and did not activate allogeneic or specific $\mathrm{T}$ cells to the same degree. The fact that the most efficient maturation mixture contained LPS could be problematic since remaining LPS in the DC vaccine may induce septic shock. We attempted to exchange LPS by MPLA, a LPS derivative reported as less toxic [23, 42], but could not reproduce the results found with intact LPS. Therefore, we believe that, in this setting, LPS has to be included to produce a vaccine able to activate tumorspecific $\mathrm{T}$ cells. However, it is essential that the vaccine is thoroughly washed and proven free of endotoxins by appropriate tests before administration to patients. Previous clinical trials have shown that it is feasible to produce a DC vaccine free from endotoxin, even when LPS is included in the production protocol, and that administration to patients was well tolerated [34, 43].

In addition to the vaccine being LPS free, it is equally important that all reagents used are of a high purity to avoid other contaminants. To our knowledge there is no GMP-grade LPS or R848 available in the market. However, for LPS we could show that the VacciGrade ${ }^{\text {TM }}$ LPS reagent from Invivogen was as potent as normal grade LPS, and we also used VacciGrade ${ }^{\mathrm{TM}} \mathrm{R} 848$. These products are produced under aseptic conditions and have been tested to ensure that they activate only the correct TLR pathway. On the other hand, we used different variants of poly I:C with variable results. We found that non-GMP-grade poly I:C was occasionally contaminated with LPS. It is possible that the results of some of the previous reports on DC matured in the presence 
of non-GMP-grade poly I:C were affected by contaminating LPS. A comparison between the IFN $\gamma$, R848, Hiltonol $\odot$, and LPS cocktail and the previously used "gold standard" (TNF $\alpha$, IL1 $\beta$, IL-6, PGE2) and "alpha type-1 DC" (TNF $\alpha$, IL-1 $\beta$, IFN $\alpha$, IFN $\gamma$, Hiltonol@) maturation cocktails showed that both latter cocktails induced only low amounts of IL12p70. This is in contrast to previous reports showing enhanced production of IL12p70 by "alpha type-1 DC" compared to "gold standard DC." The reason may be that we used the GMPgrade Hiltonol@ in the alpha-type-1 DC cocktail instead of the non-GMP-grade poly I:C used in previous publications. Furthermore, poly I:C contains different lengths of dsRNA, varying between manufacturer and batches, and this might affect the uptake and/or downstream signaling. There are several cytosolic dsRNA receptors, e.g., mda-5 and RIG-I, that in addition to the endosomal TLR-3 bind to poly I:C and activate downstream signaling. However, the length of the Poly I:C determines which of these receptors are triggered [4446]. Since we aimed to have a stable DC maturation protocol we decided to work with the long-strand, GMP-grade poly I:C Hiltonol@ which is also less prone to degradation due to addition of a poly-lysine chain.

We have recently treated late-stage melanoma patients with a combination of ACT of TIL and vaccination with tumor lysate-loaded DC [47]. This was a small phase I trial that cannot be used to draw conclusion about clinical efficacy, but one patient responded during the DC vaccination with tumor regression which is still ongoing more than 5 years later and two patients experienced stable disease for 20 and 10 months. There, we used a Mo-DC vaccine differentiated to iDC by IL-4 and GM-CSF and to $\mathrm{mDC}$ by $\mathrm{TNF} \alpha$ alone simultaneous to loading with autologous tumor lysate. Here, we compare that maturation protocol with the protocol containing IFN $\gamma, \mathrm{R} 848$, and poly I:C. Both protocols were tested with or without LPS. TNF $\alpha$-matured DC had poor capacity to activate $\mathrm{T}$ cells, even when LPS was included. This despite that they most efficiently upregulated HLA-DR and had the lowest upregulation of inhibitory PD-L1. DC matured with IFN $\gamma, \mathrm{R} 848$, and poly I:C cocktails (with or without LPS), on the other hand, expressed medium levels of HLA-DR and high levels of PD-L1, but had strong T cellactivating capacity, especially with LPS added. Furthermore, there was either no effect or a lowered response by including TNF $\alpha$ in the IFN $\gamma$, R848, and poly I:C cocktails. Thus, there is no benefit of adding TNF $\alpha$ during DC maturation.

Numerous DC maturation protocols have been previously published by other groups. In comparison with these, the IFN $\gamma, \mathrm{R} 848$, poly I:C, and LPS cocktail-matured DC rank among the best when it comes to the amount of IL12 p70 produced and the ability to activate IFN $\gamma$ production in T cells. Previous studies have shown a synergistic effect on DC IL-12p70 production by including IFN $\gamma$ [9, $19,24]$ or by combining several TLR ligands [24, 26, 27]. One study showed that melanoma patient DC matured with CD40L and IFN $\gamma$ were often deficient in IL12p70 production but that this could be counteracted by addition of the two TLR ligands R848 and poly I:C [28] and that vaccination of melanoma patients with such CD40L/IFN $\gamma /$ R848/poly I:C-matured DC loaded with neoepitope and shared peptides resulted in in vivo expansion of specific $\mathrm{T}$ cells [48]. Furthermore, another study reported improved anti-tumor activity and increased resistance to immunosuppression by tumor-reactive $\mathrm{T}$ cells expanded in vitro in the presence of anti-CD3 and allogeneic, IFN $\gamma, \mathrm{R} 848$, and poly I:C-matured DC compared to in the presence of anti-CD3 and allogeneic, irradiated bulk PBMC [49]. However, to our knowledge this is the first time a DC maturation cocktail with IFN $\gamma$ and three TLR ligands are used. In line with the previous publications, our data clearly show that the presence of IFN $\gamma$ during maturation potentiates the IL-12p70 production and thereby the T cell-activating ability of the DC. Furthermore, addition of three TLR ligands in the maturation cocktails is more efficient than two TLR ligands for generating DC with high IL-12p70, but still modest IL-10, production, and strong $\mathrm{T}$ cell-activating capacity. In line with this, DC loaded with whole tumor cell lysates and matured in the presence of IFN $\gamma$ and three, but not two, TLR ligands were shown to convincingly activate tumor antigen-specific $\mathrm{T}$ cell responses. Whether the increase in response is due to the precise TLR ligands used or just an additive effect of using several ligands has not been elucidated. However, it is clear that there is a great variation between individuals in the ability to respond to a certain TLR ligand. Using several TLR ligands should therefore increase the likelihood to generate efficient Mo-DC in most individuals. For example, in our experiments the addition of poly I:C has the smallest impact on IL12p70 production in most donors, but in donors where the LPS response is weak poly I:C strongly increased the amount of IL12p70 produced by DC and the IFN $\gamma$ produced by $\mathrm{T}$ cells in corresponding co-cultures (see donor $\mathrm{F}$ in Fig. 2). Thus, in future cancer DC vaccine clinical trials the maturation of the DC should be performed in the presence of IFN $\gamma$, R848, poly I:C, and LPS.

Acknowledgements This work was supported by The Swedish Cancer Society (R. Kiessling; 2013/379), The Cancer Society in Stockholm and The King Gustaf V's Jubilee Foundation (R. Kiessling; 144102), The Swedish Medical Research Council (R. Kiessling; 5212013-4100), Stockholm City Council Project Grant (R. Kiessling; ALF Medicin 2015, 20140036), Knut and Alice Wallenberg Foundations (R. Kiessling), O.E och Edla Johanssons vetenskapliga stiftelse (T. Lövgren), Stiftelsen Längmanska kulturfonden (T. Lövgren), and the National Institutes of Health (M. Nishimura; NIH P01 CA154778 and NIH R01 CA10494). We thank A.M. Salazar (Oncovir, Inc.) for providing Hiltonol. 


\section{Compliance with ethical standards}

Conflict of interest $\mathrm{R}$ Kiessling is in the Scientific Advisory Board for the companies Immunicum AB, Idogen Inc, Glactone Pharma AB, and Clinical Laserthermia Systems $\mathrm{AB}$, and has received compensation for arranging courses for Bristol Myers Squibb and a research grant from Moderna Therapeutics. A. Karlsson-Parra is employed by, and a shareholder of, Immunicum AB. All other authors declare that they have no conflicts of interest.

Research involving human participants and/or animals All procedures involving human participants were in accordance with the ethical standards of the institutional and national research committee and with the 1964 Helsinki declaration and its later amendments or comparable ethical standards. An ethical permission to work with buffy coats from anonymous blood donors was approved by on 2001-03-05 (No. 01-50) by the Stockholm regional ethical committee. This article does not contain any studies with animals performed by any of the authors.

Informed consent For this type of study formal consent is not required.

Open Access This article is distributed under the terms of the Creative Commons Attribution 4.0 International License (http://creativecommons.org/licenses/by/4.0/), which permits unrestricted use, distribution, and reproduction in any medium, provided you give appropriate credit to the original author(s) and the source, provide a link to the Creative Commons license, and indicate if changes were made.

\section{References}

1. Schreibelt G, Bol KF, Westdorp H et al (2016) Effective clinical responses in metastatic melanoma patients after vaccination with primary myeloid dendritic cells. Clin Cancer Res 22:2155-2166. doi:10.1158/1078-0432.Ccr-15-2205

2. Sittig SP, de Vries IJM, Schreibelt G (2015) Primary human blood dendritic cells for cancer immunotherapy-tailoring the immune response by dendritic cell maturation. Biomedicines 3:282-303. doi: $10.3390 /$ biomedicines 3040282

3. Kantoff PW, Higano CS, Shore ND et al (2010) Sipuleucel-T immunotherapy for castration-resistant prostate cancer. N Engl J Med 363:411-422. doi:10.1056/NEJMoa1001294

4. Bloy N, Pol J, Aranda F et al (2014) Trial watch: dendritic cellbased anticancer therapy. Oncoimmunology 3:e963424. doi:10.4 $161 / 21624011.2014 .963424$

5. Galluzzi L, Senovilla L, Vacchelli E et al (2012) Trial watch: dendritic cell-based interventions for cancer therapy. Oncoimmunology 1:1111-1134. doi:10.4161/onci.21494

6. Vacchelli E, Vitale I, Eggermont A et al (2013) Trial watch: dendritic cell-based interventions for cancer therapy. Oncoimmunology 2:e25771. doi:10.4161/onci.25771

7. Tureci O, Vormehr M, Diken M, Kreiter S, Huber C, Sahin U (2016) Targeting the heterogeneity of cancer with individualized neoepitope vaccines. Clin Cancer Res 22:1885-1896. doi:10.1158/1078-0432.CCR-15-1509

8. Gilboa E (2007) DC-based cancer vaccines. J Clin Invest 117:1195-1203. doi:10.1172/JCI31205

9. Mailliard RB, Wankowicz-Kalinska A, Cai Q, Wesa A, Hilkens CM, Kapsenberg ML, Kirkwood JM, Storkus WJ, Kalinski P (2004) alpha-type-1 polarized dendritic cells: a novel immunization tool with optimized CTL-inducing activity. Cancer Res 64:5934-5937. doi:10.1158/0008-5472.CAN-04-1261

10. Palucka K, Banchereau J (2013) Dendritic-cell-based therapeutic cancer vaccines. Immunity 39:38-48. doi:10.1016/j. immuni.2013.07.004

11. Jonuleit H, Kuhn U, Muller G, Steinbrink K, Paragnik L, Schmitt E, Knop J, Enk AH (1997) Pro-inflammatory cytokines and prostaglandins induce maturation of potent immunostimulatory dendritic cells under fetal calf serum-free conditions. Eur J Immunol 27:3135-3142. doi:10.1002/eji.1830271209

12. Kalinski P, Vieira PL, Schuitemaker JH, de Jong EC, Kapsenberg ML (2001) Prostaglandin E(2) is a selective inducer of interleukin-12 p40 (IL-12p40) production and an inhibitor of bioactive IL-12p70 heterodimer. Blood 97:3466-3469

13. Iwasaki A, Medzhitov R (2004) Toll-like receptor control of the adaptive immune responses. Nat Immunol 5:987-995. doi:10.1038/ni1112

14. Jarrossay D, Napolitani G, Colonna M, Sallusto F, Lanzavecchia A (2001) Specialization and complementarity in microbial molecule recognition by human myeloid and plasmacytoid dendritic cells. Eur J Immunol 31:33883393. doi:10.1002/1521-4141(200111)31:11<3388:AIDIMMU3388>3.0.CO;2-Q

15. Kadowaki N, Ho S, Antonenko S, Malefyt RW, Kastelein RA, Bazan F, Liu YJ (2001) Subsets of human dendritic cell precursors express different toll-like receptors and respond to different microbial antigens. J Exp Med 194:863-869

16. Kokkinopoulos I, Jordan WJ, Ritter MA (2005) Toll-like receptor mRNA expression patterns in human dendritic cells and monocytes. Mol Immunol 42:957-968. doi:10.1016/j. molimm.2004.09.037

17. Visintin A, Mazzoni A, Spitzer JH, Wyllie DH, Dower SK, Segal DM (2001) Regulation of toll-like receptors in human monocytes and dendritic cells. J Immunol 166:249-255

18. Zobywalski A, Javorovic M, Frankenberger B, Pohla H, Kremmer E, Bigalke I, Schendel DJ (2007) Generation of clinical grade dendritic cells with capacity to produce biologically active IL-12p70. J Transl Med 5:18. doi:10.1186/1479-5876-5-18

19. Lehner M, Morhart P, Stilper A, Petermann D, Weller P, Stachel D, Holter W (2007) Efficient chemokine-dependent migration and primary and secondary IL-12 secretion by human dendritic cells stimulated through Toll-like receptors. J Immunother 30:312-322. doi:10.1097/01.cji.0000211345.11707.46

20. Han TH, Jin P, Ren J, Slezak S, Marincola FM, Stroncek DF (2009) Evaluation of 3 clinical dendritic cell maturation protocols containing lipopolysaccharide and interferon-gamma. J Immunother 32:399-407. doi:10.1097/CJI.0b013e31819e1773

21. Vopenkova K, Mollova K, Buresova I, Michalek J (2012) Complex evaluation of human monocyte-derived dendritic cells for cancer immunotherapy. J Cell Mol Med 16:2827-2837. doi:10.1111/j.1582-4934.2012.01614.x

22. Koski GK, Koldovsky U, Xu S et al (2012) A novel dendritic cell-based immunization approach for the induction of durable Th1-polarized anti-HER-2/neu responses in women with early breast cancer. J Immunother 35:54-65. doi:10.1097/ CJI.0b013e318235f512

23. Massa C, Seliger B (2013) Fast dendritic cells stimulated with alternative maturation mixtures induce polyfunctional and long-lasting activation of innate and adaptive effector cells with tumor-killing capabilities. J Immunol 190:3328-3337. doi:10.4049/jimmunol.1202024

24. Napolitani G, Rinaldi A, Bertoni F, Sallusto F, Lanzavecchia A (2005) Selected toll-like receptor agonist combinations synergistically trigger a $\mathrm{T}$ helper type 1-polarizing program in dendritic cells. Nat Immunol 6:769-776. doi:10.1038/ni1223 
25. Bergqvist L, Holmgren S, Johnson S et al (2008) The TLR8 agonist R848 primes human monocyte-derived dendritic cells for a secondary, CD40-dependent, burst of IL-12p70 production. Cancer Immunol Immunother 57(Supplement 1):S9-S10 (Abstract)

26. Boullart AC, Aarntzen EH, Verdijk P et al (2008) Maturation of monocyte-derived dendritic cells with toll-like receptor 3 and $7 / 8$ ligands combined with prostaglandin E2 results in high interleukin-12 production and cell migration. Cancer Immunol Immunother 57:1589-1597. doi:10.1007/s00262-008-0489-2

27. Makela SM, Strengell M, Pietila TE, Osterlund P, Julkunen I (2009) Multiple signaling pathways contribute to synergistic TLR ligand-dependent cytokine gene expression in human monocyte-derived macrophages and dendritic cells. J Leukoc Biol 85:664-672. doi:10.1189/jlb.0808503

28. Carreno BM, Becker-Hapak M, Huang A et al (2013) IL12p70-producing patient DC vaccine elicits Tc1-polarized immunity. J Clin Invest 123:3383-3394. doi:10.1172/JCI68395

29. Roszkowski JJ, Lyons GE, Kast WM, Yee C, Van Besien K, Nishimura MI (2005) Simultaneous generation of CD8+ and $\mathrm{CD} 4+$ melanoma-reactive $\mathrm{T}$ cells by retroviral-mediated transfer of a single T-cell receptor. Cancer Res 65:1570-1576. doi:10.1158/0008-5472.CAN-04-2076

30. Nishimura MI, Avichezer D, Custer MC et al (1999) MHC class I-restricted recognition of a melanoma antigen by a human CD4+ tumor infiltrating lymphocyte. Cancer Res 59:6230-6238

31. Anguille S, Smits EL, Cools N, Goossens H, Berneman ZN, Van Tendeloo VF (2009) Short-term cultured, interleukin-15 differentiated dendritic cells have potent immunostimulatory properties. J Transl Med 7:109. doi:10.1186/1479-5876-7-109

32. Beck B, Dorfel D, Lichtenegger FS, Geiger C, Lindner L, Merk M, Schendel DJ, Subklewe M (2011) Effects of TLR agonists on maturation and function of 3-day dendritic cells from AML patients in complete remission. J Transl Med 9:151. doi:10.1186/1479-5876-9-151

33. Burdek M, Spranger S, Wilde S, Frankenberger B, Schendel DJ, Geiger C (2010) Three-day dendritic cells for vaccine development: antigen uptake, processing and presentation. J Transl Med 8:90. doi:10.1186/1479-5876-8-90

34. Chiang CL, Hagemann AR, Leskowitz R, Mick R, Garrabrant T, Czerniecki BJ, Kandalaft LE, Powell DJ Jr, Coukos G (2011) Day-4 myeloid dendritic cells pulsed with whole tumor lysate are highly immunogenic and elicit potent anti-tumor responses. PLoS One 6:e28732. doi:10.1371/journal.pone.0028732

35. Czerniecki BJ, Carter C, Rivoltini L et al (1997) Calcium ionophore-treated peripheral blood monocytes and dendritic cells rapidly display characteristics of activated dendritic cells. J Immunol 159:3823-3837

36. Dauer M, Lam V, Arnold H, Junkmann J, Kiefl R, Bauer C, Schnurr M, Endres S, Eigler A (2008) Combined use of toll-like receptor agonists and prostaglandin $\mathrm{E}(2)$ in the FastDC model: rapid generation of human monocyte-derived dendritic cells capable of migration and IL-12p70 production. J Immunol Methods 337:97-105. doi:10.1016/j.jim.2008.07.003

37. Frankenberger B, Schendel DJ (2012) Third generation dendritic cell vaccines for tumor immunotherapy. Eur J Cell Biol 91:5358. doi:10.1016/j.ejcb.2011.01.012
38. Lichtenegger FS, Mueller K, Otte B, Beck B, Hiddemann W, Schendel DJ, Subklewe M (2012) CD86 and IL-12p70 are key players for $\mathrm{T}$ helper 1 polarization and natural killer cell activation by toll-like receptor-induced dendritic cells. PLoS One 7:e44266. doi:10.1371/journal.pone.0044266

39. Adamson L, Palma M, Choudhury A et al (2009) Generation of a dendritic cell-based vaccine in chronic lymphocytic leukaemia using CliniMACS platform for large-scale production. Scand J Immunol 69:529-536. doi:10.1111/j.1365-3083.2009.02249.x

40. Palmer DH, Midgley RS, Mirza N et al (2009) A phase II study of adoptive immunotherapy using dendritic cells pulsed with tumor lysate in patients with hepatocellular carcinoma. Hepatology 49:124-132. doi:10.1002/hep.22626

41. Zahradova L, Mollova K, Ocadlikova D et al (2012) Efficacy and safety of Id-protein-loaded dendritic cell vaccine in patients with multiple myeloma—phase II study results. Neoplasma 59:440 449. doi:10.4149/neo_2012_057

42. Casella CR, Mitchell TC (2008) Putting endotoxin to work for us: monophosphoryl lipid $\mathrm{A}$ as a safe and effective vaccine adjuvant. Cell Mol Life Sci 65:3231-3240. doi:10.1007/ s00018-008-8228-6

43. Palucka AK, Ueno H, Fay JW, Banchereau J (2010) LPS-activated dendritic cell vaccine in combination with immunomodulatory dose of cytoxan in patients with stage IV melanoma: phase I/IIa clinical trial. J Clin Oncol 28(suppl):TSP313 (abstr)

44. Gitlin L, Barchet W, Gilfillan S, Cella M, Beutler B, Flavell RA, Diamond MS, Colonna M (2006) Essential role of mda-5 in type I IFN responses to polyriboinosinic:polyribocytidylic acid and encephalomyocarditis picornavirus. Proc Natl Acad Sci USA 103:8459-8464. doi:10.1073/pnas.0603082103

45. Kato H, Sato S, Yoneyama M et al (2005) Cell type-specific involvement of RIG-I in antiviral response. Immunity 23:19-28. doi:10.1016/j.immuni.2005.04.010

46. Kato H, Takeuchi O, Mikamo-Satoh E et al (2008) Lengthdependent recognition of double-stranded ribonucleic acids by retinoic acid-inducible gene-I and melanoma differentiationassociated gene 5. J Exp Med 205:1601-1610. doi:10.1084/ jem.20080091

47. Poschke I, Lovgren T, Adamson L, Nystrom M, Andersson E, Hansson J, Tell R, Masucci GV, Kiessling R (2014) A phase I clinical trial combining dendritic cell vaccination with adoptive $\mathrm{T}$ cell transfer in patients with stage IV melanoma. Cancer Immunol Immunother 63:1061-1071. doi:10.1007/s00262-014-1575-2

48. Carreno BM, Magrini V, Becker-Hapak M et al (2015) Cancer immunotherapy. A dendritic cell vaccine increases the breadth and diversity of melanoma neoantigen-specific T cells. Science 348:803-808. doi:10.1126/science.aaa3828

49. Jin C, Yu D, Hillerdal V, Wallgren A, Karlsson-Parra A, Essand M (2014) Allogeneic lymphocyte-licensed DCs expand T cells with improved antitumor activity and resistance to oxidative stress and immunosuppressive factors. Mol Ther Methods Clin Dev 1:14001. doi:10.1038/mtm.2014.1 